Int. J. Electrochem. Sci., 12 (2017) 10642 - 10659

International Journal of

ELECTROCHEMICAL

SCIENCE

www.electrochemsci.org

\title{
Ultrasensitive Detection of Nitrite Based on gold-nanoparticles/ Polyrhodamine B/Carbon Nanotubes Modified Glassy Carbon Electrode with Enhanced Electrochemical Performance
}

\author{
He Xu* , Jiachao Peng, Mengting Zhu, Jianshe Liu \\ College of Environmental Science and Engineering, Donghua University, Shanghai 201620, P R China \\ *E-mail: $\underline{\text { hexu@dhu.edu.cn }}$
}

doi: $10.20964 / 2017.11 .48$

Received: 27 July 2017 / Accepted: 5 September 2017 / Published: 12 October 2017

\begin{abstract}
An electrochemical sensing platform based on gold nanoparticles/polyrhodamine B/multi-walled carbon nanotubes composites modified glassy carbon electrode (AuNPs/PRhB/MWCNTs/GCE) was developed for the ultrasensitive determination of nitrite. The morphology and properties of resulting composites were characterized by scanning electron microscopy (SEM) and energy dispersive X-ray spectroscopy (EDX) and electrochemical techniques. Compared with individual PRhB/GCE or MWCNTs/GCE, the AuNPs/PRhB/MWCNTs/GCE sensor exhibited faster electron transfer and better electrocatalytic activity towards the oxidation of nitrite, mainly due to the strong synergistic effect of conducting polymer, metal nanoparticles and carbon nanotubes. Oxidation of nitrite was effectively electrocatalyzed at AuNPs/PRhB/MWCNTs/GCE with significant increase in oxidation current (109\%, 79\% and 53\% in comparison with PRhB/GCE, MWCNTs/GCE and PRhB/MWCTs/GCE) and with considerable decrease in the oxidation potential $(0.124,0.118$ and $0.111 \mathrm{~V}$ in comparison with $\mathrm{PRhB} / \mathrm{GCE}$, MWCNTs/GCE and PRhB/MWCTs/GCE, respectively). The oxidation peak current of nitrite was linearly proportional to its concentration with multi-linear ranges of $1 \sim 25 \mu \mathrm{M}\left(\mathrm{R}^{2}=\right.$ $0.9922)$ and $35 \mu \mathrm{M} \sim 10 \mathrm{mM}\left(\mathrm{R}^{2}=0.9947\right)$ by differential pulse voltammetry (DPV). Lower concentration of nitrite was detected by amperometry with the linear ranges of $0.1 \sim 5 \mu \mathrm{M}\left(\mathrm{R}^{2}=\right.$ $0.9973)$ and $0.02 \sim 0.16 \mu \mathrm{M}\left(\mathrm{R}^{2}=0.9994\right)$, and the limit of detection was as low as $6.7 \mathrm{nM}(\mathrm{S} / \mathrm{N}=3)$. Furthermore, the constructed sensor demonstrated the long-term stability, good reproducibility and excellent anti-interference properties, and it was successfully applied in analysis of nitrite in real samples and gained good testing recoveries of $99 \% \sim 104.5 \%$.
\end{abstract}

Keywords: electrochemical oxidation; nitrite; polyrhodamine B; electrodeposition; chemical modified electrode

$\underline{\text { FULL TEXT }}$ 
(C) 2017 The Authors. Published by ESG (www.electrochemsci.org). This article is an open access article distributed under the terms and conditions of the Creative Commons Attribution license (http://creativecommons.org/licenses/by/4.0/). 